\title{
Harnessing PET Wastes by Compounding with Functionalized Flax
}

\author{
Denisa Ficai $^{1}$, Maria Sonmez ${ }^{2}$, Anton Ficai ${ }^{1}$, Ioana Lavinia Ardelean ${ }^{1}$, Ecaterina Andronescu $^{1}$ \\ ${ }^{1}$ Department of Science and Engineering of Oxide Materials and Nanomaterials, Faculty of Applied Chemistry and \\ Materials Science, University Politehnica of Bucharest \\ Polizu Street no 1-7, 011061, Bucharest, Romania \\ denisa.ficai@upb.ro; ficaimaria@yahoo.com \\ ${ }^{2}$ National Research and Development Institute for Textiles and Leather-division: \\ Leather and Footwear Research Institute, Bucharest, Romania
}

\section{Extended Abstract}

Plastic wastes are generated by a variety of sources, including consumer goods, packaging, automotive, electrical and electronic industries, leading to significant growth in the volume of wastes and the impetuous need of their management [1]. The storage of plastic wastes is extremely difficult and has become a social problem in recent years, globally [2]. Recycling these products, is considered one of the best ways to save and protect the environment, although, applied technologies must be designed and managed to avoid environmental pollution especially because the half-life of most plastics is of tens of years [3]. For this purpose, special attention must be paid to recycling polyethylene terephthalate (PET) because it is the polymer most commonly used worldwide as packaging material for water as well as other drinks. Compared with other types of waste from polymer materials, PET can be easily collected, recycled and turned into new value-added products in industrial applications (not for food applications).

In order to improve physical, mechanical and thermal properties of the products derived from PET wastes, the polymer melt was reinforced with surface modified flax fibres and fabrics. In this study two routes of flax fabric functionalization with adequate titanium and aluminum precursors are presented. The first synthesis route involves the treatment of the cellulosic material with the precursor $\left(\mathrm{AlCl}_{3}\right.$ or $\left.\mathrm{Ti}\left(\mathrm{C}_{4} \mathrm{H}_{9} \mathrm{O}\right)_{4}\right)$, followed by precipitation of the $\mathrm{Al}_{2} \mathrm{O}_{3}$ or $\mathrm{TiO}_{2}$ by addition of an aqueous $1 \mathrm{M} \mathrm{NaOH}$ solution (when use $\mathrm{AlCl}_{3}$ ) or water (when use titanium butoxide). Under these conditions, the precipitation reaction occurs also in solution part of the ceramic powder is not deposited on the fiber / fabric. The second synthesis route consists in treating the fibers / fabrics with water or sodium hydroxide solution, then, by contact with the precursors $\mathrm{Al}_{2} \mathrm{O}_{3}$ and $\mathrm{TiO}_{2}$ are obtained, but, because of the fast precipitation rate, a lot of the precursor precipitate without adhering to the fabric surface. These functionalization was done in order to be further used for obtaining

The modified in fabrics, was analyzed both visually and instrumentally. It can be seen that the processing route and the used functionalizing agent induce important morphological changes of the fabric surface. If functionalization occurs with alumina precursor the deposited mineral phase is relatively homogeneous distributed on the surface of the fabric. In the case of functionalization with titanium butoxide, the morphology of the surface is strongly dependent on the order of addition of the reactants. The best adherence of $\mathrm{TiO}_{2}$ nanoparticles occurs during the second functionalization routes as it can be visualized in SEM and FTIR microscopy.

The composite materials obtained from flax and PET wastes exhibit good properties and thus can be considered valuable raw materials for obtaining composite materials for automotive parts, protective plates for highways and railways, for instance.

\section{References}

[1] U. Riedel, J.Nickel. Applications of natural fiber composites for constructive parts in aerospace, automobiles, and other areas, Book Chapter, Germany, pp. 1-11, 2010.

[2] A. Nagy, W. Uriciuc, E. Nagy, "Evaluation of plastics recycling of terms of ecoefficiency," 13th National Multidisciplinary Conference, Professor Dorin Pavel, Sebes, Romania, pp. 207-214, 2013.

[3] J. Sahari, S.M. Sapuan, "Natural fibre reinforced biodegradable polymer composites," Rev. Adv. Mater. Sci., vol. 30, pp. 166-174, 2011. 